\title{
Erratum
}

\section{Muscle Weakness Following Eccentric Work in Man}

\section{T. M. Davies and M. J. White}

Pflügers Arch (1981) 392:168-171

Page 169: The last sentence should read "Thus if the ratio of the $20 \mathrm{~Hz}$ to the $50 \mathrm{~Hz} \ldots$ " not "200 $\mathrm{Hz}$ to the $50 \mathrm{~Hz}$ ".

Page 170: In the Discussion, second paragraph, the sentence starting "In negative work muscle temperature $\left(T_{\mathrm{m}}\right)$ rises to a greater extent than in positive exercise [9]" should continue "and though $T_{\mathrm{m}}$ was not measured...". 